\title{
A well-characterised peak identification list of MALDI MS profile peaks for human blood serum
}

Article

Accepted Version

Tiss, A., Smith, C., Menon, U., Jacobs, I., Timms, J. F. and Cramer, R. (2010) A well-characterised peak identification list of MALDI MS profile peaks for human blood serum. Proteomics, 10 (18). pp. 3388-3392. ISSN 1615-9853 doi: https://doi.org/10.1002/pmic.201000100 Available at https://centaur.reading.ac.uk/8227/

It is advisable to refer to the publisher's version if you intend to cite from the work. See Guidance on citing.

To link to this article DOI: http://dx.doi.org/10.1002/pmic.201000100

Publisher: WILEY-VCH Verlag

All outputs in CentAUR are protected by Intellectual Property Rights law, including copyright law. Copyright and IPR is retained by the creators or other copyright holders. Terms and conditions for use of this material are defined in the End User Agreement.

www.reading.ac.uk/centaur 
Central Archive at the University of Reading

Reading's research outputs online 


\title{
Dataset Brief
}

\section{A Well-Characterised Peak Identification List of MALDI MS Profile Peaks for Human Blood Serum}

\author{
Ali Tiss ${ }^{1}$, Celia Smith ${ }^{1}$, Usha Menon ${ }^{2}$, Ian Jacobs ${ }^{2}$, John F. Timms ${ }^{2}$ and Rainer Cramer ${ }^{*}$ \\ ${ }^{1}$ The BioCentre and Department of Chemistry, University of Reading, Reading, UK \\ ${ }^{2}$ Institute for Women's Health, UCL, London, UK \\ *Address correspondence to: \\ Prof Rainer Cramer, The BioCentre and Department of Chemistry, University of Reading, \\ Whiteknights, PO Box 221, Reading, RG6 6AS, UK. \\ Tel.: +44-118-378-4550; FAX: +44-118-378-4551; e-mail: r.k.cramer@rdg.ac.uk
}

Non-standard abbreviations: UKCTOCS, United Kingdom Collaborative Trial of Ovarian Cancer Screening; UKOPS, United Kingdom Ovarian Cancer Population Study.

Keywords: MALDI, mass spectrometry, MS peak identification, serum profiling 
MALDI MS profiling, using easily available body fluids such as blood serum, has attracted considerable interest for its potential in clinical applications. Despite the numerous reports on MALDI MS profiling of human serum there is only scarce information on the identity of the species making up these profiles, particularly in the mass range of larger peptides. Here we provide a list of more than 90 entries of MALDI MS profile peak identities up to $10 \mathrm{kDa}$ obtained from human blood serum. Various modifications such as phosphorylation were detected amongst the peptide identifications. The overlap with the few other MALDI MS peak lists published so far was found to be limited and hence our list significantly extends the number of identified peaks commonly found in MALDI MS profiling of human blood serum. 
There has been great interest in exploiting simple MALDI MS profiling for the analysis of crude or little purified human serum or plasma samples for clinical diagnostics [1, 2]. However, it has become apparent that there are far more challenges related to its applicability to disease diagnosis than initially thought. The experimental bias and the sensitivity and diagnostic accuracy of MALDI MS profiling are of major concern $[3,4]$. These are further aggravated by the wide range of abundances and the complexity of the endogenous molecular components in blood [2]. However, there have been now further reports substantiating the claim that MALDI MS profiling can indeed be a tool for disease (outcome) classification [5] and biomarker discovery [6].

The fact that little is known about most of these potential biomarkers presents a serious limitation for quantification and validation of potentially discriminatory peaks and restricts biomarker assay development, including immunoassays that might potentially overcome some of the above analytical limitations of MALDI MS profiling.

Unlike the in-depth analyses of human blood serum or plasma where many hundreds of peptides and proteins have been identified [7, 8], MALDI MS profiling focuses on the reproducible, rapid and inexpensive acquisition of MS peak patterns that can be used for discriminative analysis as needed in population screening or clinical triage.

Employing MALDI, peptide sequencing is more challenging and usually less sensitive and informative for identification purposes than ESI-LC-MS/MS which is mostly combined with extensive prefractionation but without any relation to MALDI MS profiles [9, 10]. Indeed, only a few identifications of MALDI MS profile peaks have been reported so far. The most comprehensive list of peptide identifications obtained from human blood serum was reported by Villanueva et al. [11], although it provides only peak identifications below 4 kDa. For blood plasma, Koomen et al. [12] reported a list of 249 sequenced plasma profile peptides with a maximum mass of $5.2 \mathrm{kDa}$. 
In the present study, we used serum blood samples from healthy persons recruited as part of the United Kingdom Collaborative Trial of Ovarian Cancer Screening (UKCTOCS) and United Kingdom Ovarian Cancer Population Study (UKOPS) (for details, see [13]). Polypeptides were enriched from $5 \mu \mathrm{L}$ of serum using a one-step protocol based on reversed phase pre-packed C18-ZipTips ${ }^{\circledR}$. The eluates from this one-step preparation were used for this study. The acquired MS/MS data are available in the PRIDE database (Experiment Accession \# 11692-11694). Details on the materials and methods employed can be found in Supplemental Data 1.

MALDI-TOF MS profiling of 60 serum samples revealed 108 aligned peaks within the combined UKCTOCS and UKOPS serum sample set, using an S/N ratio above 5 (Supplemental Data 2, A) and 156 peaks at $\mathrm{S} / \mathrm{N}>3$. Despite the high number of common peaks, the different sample collection and handling protocols for the UKOPS and UKCTOCS sample sets resulted in markedly different MALDI MS profiles and peak intensities (Figure 1). Thus, sera from both sample sets were employed to identify as many profile peaks as possible using the higher mass accuracy and sequencing capability of MALDI Q-TOF instrumentation.

Many of the peak identifications were obtained by direct switching from MALDI MS to MALDI CID MS/MS as described in Supplemental Data 1, analysing the precursor ions determined in the MALDI MS profile. This approach provided a total of 36 identities through searching the human subset of the NCBInr protein database using MASCOT with an average mass accuracy of the precursor ion mass measurements of 13 ppm (Supplemental Data 2, B). The next approach was using the same samples for nanoESI MS/MS analysis, using the chip-based Nanomate system. Similarly to the MALDI analysis, MS profile spectra were first acquired and MS/MS analysis of the precursor ions of the MS profile provided their identity. In this approach, the MALDI and ESI MS profiles were compared to match peaks unambiguously and a total of 16 peaks were identified, of which 6 could not be identified by earlier MALDI MS/MS analysis. 
Next, the serum sample eluates were fractionated by off-line C18 reversed-phase chromatography and the fractions were analysed by chip-based nanoESI as before. In contrast to many previous reports using major-protein depletion or multi-dimensional separation strategies where 200-400 peptides were identified $[9,10,12]$, the objective of our fractionation strategy was to enhance the identification of peptides but to ensure that the obtained identities are the correct identities of the MALDI MS profile peaks. In all large-scale serum proteomic studies published so far this has not been achieved and can therefore result in a high false positive rate. Thus, we also monitored the change of the MALDI MS profile after fractionation by comparing the pre-fractionation MALDI MS profile with the MALDI MS (and ESI MS) profiles of each fraction. The fractions were then analysed by chip-based nanoESI MS/MS and MASCOT searching of the MS/MS data resulted in an additional 28 identities and another 9 confirmations of identities obtained by the two earlier approaches without LC fractionation.

As expected for peaks above $\mathrm{m} / \mathrm{z} 4,500$, none of these approaches led to unambiguous peptide identification. The collected LC fractions were therefore digested with trypsin and analysed by chipbased nanoESI MS/MS. For each fraction, the protein hits from these MASCOT searches were then used to search peptide profile peaks from the undigested fractions for sequence mass matches within a mass tolerance of $50 \mathrm{ppm}$. Any putative matches were further interrogated by their isotopomer distribution, their known post-translational modifications and the likelihood of occurrence derived from their structural and functional information in protein databases. Where possible, fragment ion spectra from the previous methods were also used to substantiate putative identities. Overall, this approach led to an additional 11 peak identities.

In total, more than 80 polypeptides were identified with high confidence, representing peptides from 13 different but highly abundant proteins (see Supplemental Data 2, B). Among these there were three full length proteins, Apoliprotein CII (Apo CII), Apolipoprotein CIII (Apo CIII) and Connective tissue- 
activating peptide III (CTAP-III). The peaks at m/z 1547 and 1616 were clearly identified by both MALDI MS/MS and ESI MS/MS without LC fractionation, and correspond to Fibrinopeptide A fragments phosphorylated at serine (see Supplemental Data 3, (a)-(d)). Interestingly, many of the Fibrinopeptide A/B peaks and others show a loss of $17 \mathrm{Da}$ (ammonia) and sometimes of water. Some of the identified peptides/proteins were found to be oxidised and they were excluded from the list since many of them did not appear in the MALDI MS profiles and were most likely products obtained from the sample handling. This clearly shows that the MS peaks/profiles can substantially change with complex sample preparation methods, underlining the need for careful profile peak identification that is different to peptide identification of in-depth proteomic serum analyses.

A detailed comparison of our peak list with the peak lists reported by Villanueva et al. [11] and Peng et al. [14] shows that the lists are complementary rather than redundant (see Figure 2 and Table 1). It is worth noting that although the number of identified peaks from this study is comparable to the number reported by Villaneuva et al. [11], only about 30\% (25 peaks) are common between the two lists (Figure 2). Furthermore, the present study was able to identify nine polypeptides in the mass range of 4-10 kDa. However, within this mass range there were many more polypeptides for which the parent protein was identified after digestion but the data was inconclusive for assigning single identities to the MALDI MS profile peaks.

A comparison with a list of plasma peptide identifications reported by Koomen et al. [12] shows that again only about 25 peaks are common (about $10 \%$ of the 249 peptide identifications), reflecting the inherent difference between blood plasma and serum.

Combining this peak list with the lists from Villanueva et al. [11] and Peng et al. [14] increases the number of identified polypeptides of MALDI MS serum profiles to 139 (Table 1). This provides an extensive list of peptide identifications obtained from human blood serum that can be used for 
provisional identification of MALDI MS profiling peaks below $10 \mathrm{kDa}$ through simple comparison. Furthermore, this will allow, by quick comparison of MS profile and/or MS/MS data, the identification of many potential biomarkers commonly listed in reports without identification and thus facilitate biomarker validation.

The analysis of some of the MALDI MS profiling peaks resulted in MS/MS spectra different to those usually found for peptides (Supplemental Data 3, (e)-(f)). These fragmentation spectra were typical for phospholipids and their identification was carried out by comparing their accurate masses (within 10 ppm) to the calculated masses obtained from the LipidMaps database (www.lipidmaps.org). The presence of ion fragments at $\mathrm{m} / \mathrm{z} 86.10,104.11$ and 184.07 in all MS/MS spectra is characteristic for choline, $\mathrm{H}_{2} \mathrm{O}$-choline and phosphocholine, respectively (see Supplemental Data 3, (e)-(f), and Supplemental Data 2, C), and confirmed that these peaks are derived from phosphocholine lipids.

Interestingly, a comparison with a recently published list of endogenous serum peptides that were obtained by extensive prefractionation and ESI-MS/MS shows that more than $40 \%$ of the fribrinogen (P02671) peptides in Table 1 were not identified despite the much higher number of identified peptides $(>1000)$ obtained in that study [15]. Other comparisons including lists of endogenous plasma peptides [16] and other proteins showed similar results. In addition, none of these lists include any posttranslational modifications (PTMs), and only recently a few phosphorylated endogenous serum peptides were reported [17]. The presented list is based on MALDI MS profile peak identification and as such includes PTMs as well as other non-peptidic components. The focus on MALDI MS profile peak identification also provides an additional and decisive advantage. While other lists might provide many more endogenous peptides, these are not linked to MALDI MS profiling. As a result entries cannot be ranked according to their signal intensity in MALDI MS profiles and many of the entries will have the same mass value within a given mass tolerance. For instance, the above comparison (based 
only on fibrinogen peptides) reveals that the profile peak at $\mathrm{m} / \mathrm{z} 1518.7$ would have been wrongly assigned using the more extensive list of endogenous serum peptides published by Bakun et al. [15]. In the latter, the peptide at the corresponding mass was identified as NRGDSTFESKSYK (cf. Table 1). In the same list, there is no entry for the serine-phosphorylated peptide DSGEGDFLAEGGGV or for its associated peptide that has lost phosphoric acid, which has the same mass value as NRGDSTFESKSYK within a tolerance of $25 \mathrm{ppm}$. In addition, the peptide entries for the profile peak at $\mathrm{m} / \mathrm{z} 1309.6$ would have led to an ambiguous identification of either SSSYSKQFTSST or DSGEGDFLAEGGGV, again assuming a mass accuracy of around 25ppm or more. Even at 10ppm most fibrinogen peptides are not unique for their respective mass value. For instance, there are seven fibrinogen peptides with exactly the same $\mathrm{m} / \mathrm{z}$ value of 1206.57 . The above analysis clearly shows that any list of endogenous serum peptides can only be useful for MALDI MS profiling if the peak identifications can be directly linked to the MALDI MS profiles.

In general, a comparison with the published literature shows that this new list of MALDI serum profile peak identifications can be highly advantageous. It can be used for initial putative peak identification, particularly where similar strict sample handling procedures have been followed. Recently published MALDI serum profiling work [18] using FT-ICR-MS for the identification of acute leukemia biomarker candidate peaks at m/z 1778 and 1865 revealed these peaks to be fragments of complement C3f as listed in Table 1. Other examples can be found for the average $\mathrm{m} / \mathrm{z} 1212,1350,1451,1564$, 1691, 1779, 1866 [19]; 3275 [20]; 1467 [21]; 5905 [22]; and 4283 [23]. Some of these profile peaks were even obtained from blood plasma. Nonetheless, one needs to be aware that the presented dataset is based on the analysis of C18-purified but otherwise non-fractionated serum and that its application to plasma or fractionated serum MS profile peaks may be limited. Some of the limitation with respect to sample handling can be seen in the comparison with the data from Villanueva et al. and Peng et al. (Table 1 and Figure 2). However, there are many reasons for the low degree of overlap between these 
three studies. In our study we identified non-peptidic and larger peptide peaks and used exclusively healthy persons while the other two studies either focused on peptide identification of cancer-specific profile peaks or used SELDI chips for serum fractionation. Within our study we tried to extend the currently available and biased lists by employing a sample handling protocol that researchers in the field consider as best practice and performing peak identification that is not based on disease-specific biomarker candidates.

In conclusion, the presented dataset provides the identification of more than 90 serum MALDI MS profiling peaks with little overlap with already published datasets. The more than 80 identified polypeptides originate from only 13 proteins. Complementary to other published lists this dataset also provides the identification of very low molecular weight $(<1 \mathrm{kDa})$ peaks often associated with phospholipids and peaks above $5 \mathrm{kDa}$. Together with previously published data the most comprehensive MALDI MS serum profiling list consisting of 148 peak identifications is now available (see Table 1). 
[1] Callesen, A. K., Madsen, J. S., Vach, W., Kruse, T. A., et al., Serum protein profiling by solid phase extraction and mass spectrometry: a future diagnostics tool? Proteomics 2009, 9, 1428-1441.

[2] Anderson, N. L., Anderson, N. G., The human plasma proteome: history, character, and diagnostic prospects. Mol Cell Proteomics 2002, 1, 845-867.

[3] Villanueva, J., Philip, J., Chaparro, C. A., Li, Y., et al., Correcting common errors in identifying cancer-specific serum peptide signatures. J Proteome Res 2005, 4, 1060-1072.

[4] West-Norager, M., Kelstrup, C. D., Schou, C., Hogdall, E. V., et al., Unravelling in vitro variables of major importance for the outcome of mass spectrometry-based serum proteomics. J Chromatogr B Analyt Technol Biomed Life Sci 2007, 847, 30-37.

[5] Taguchi, F., Solomon, B., Gregorc, V., Roder, H., et al., Mass spectrometry to classify non-smallcell lung cancer patients for clinical outcome after treatment with epidermal growth factor receptor tyrosine kinase inhibitors: a multicohort cross-institutional study. J Natl Cancer Inst 2007, 99, 838-846.

[6] Fiedler, G. M., Leichtle, A. B., Kase, J., Baumann, S., et al., Serum peptidome profiling revealed platelet factor 4 as a potential discriminating Peptide associated with pancreatic cancer. Clin Cancer Res 2009, 15, 3812-3819.

[7] Omenn, G. S., States, D. J., Adamski, M., Blackwell, T. W., et al., Overview of the HUPO Plasma Proteome Project: results from the pilot phase with 35 collaborating laboratories and multiple analytical groups, generating a core dataset of 3020 proteins and a publicly-available database. Proteomics 2005, $5,3226-3245$.

[8] Schenk, S., Schoenhals, G. J., de Souza, G., Mann, M., A high confidence, manually validated human blood plasma protein reference set. BMC Med Genomics 2008, 1, 41. 
[9] Harper, R. G., Workman, S. R., Schuetzner, S., Timperman, A. T., Sutton, J. N., Low-molecularweight human serum proteome using ultrafiltration, isoelectric focusing, and mass spectrometry. Electrophoresis 2004, 25, 1299-1306.

[10] Tirumalai, R. S., Chan, K. C., Prieto, D. A., Issaq, H. J., et al., Characterization of the low molecular weight human serum proteome. Mol Cell Proteomics 2003, 2, 1096-1103.

[11] Villanueva, J., Shaffer, D. R., Philip, J., Chaparro, C. A., et al., Differential exoprotease activities confer tumor-specific serum peptidome patterns. J Clin Invest 2006, 116, 271-284.

[12] Koomen, J. M., Li, D., Xiao, L. C., Liu, T. C., et al., Direct tandem mass spectrometry reveals limitations in protein profiling experiments for plasma biomarker discovery. J Proteome Res 2005, 4, 972-981.

[13] Timms, J. F., Cramer, R., Camuzeaux, S., Tiss, A., et al., Peptides generated ex vivo from serum proteins by tumor-specific exopeptidases are not useful biomarkers in ovarian cancer. Clin Chem, 56, $262-271$.

[14] Peng, J., Stanley, A. J., Cairns, D., Selby, P. J., Banks, R. E., Using the protein chip interface with quadrupole time-of-flight mass spectrometry to directly identify peaks in SELDI profiles--initial evaluation using low molecular weight serum peaks. Proteomics 2009, 9, 492-498.

[15] Bakun, M., Karczmarski, J., Poznanski, J., Rubel, T., et al., An integrated LC-ESI-MS platform for quantitation of serum peptide ladders. Application for colon carcinoma study. Proteomics Clinical Applications 2009, 3, 932-946. 
[16] Antwi, K., Hostetter, G., Demeure, M. J., Katchman, B. A., et al., Analysis of the plasma peptidome from pancreas cancer patients connects a peptide in plasma to overexpression of the parent protein in tumors. J Proteome Res 2009, 8, 4722-4731.

[17] Hu, L., Zhou, H., Li, Y., Sun, S., et al., Profiling of endogenous serum phosphorylated peptides by titanium (IV) immobilized mesoporous silica particles enrichment and MALDI-TOFMS detection. Anal Chem 2009, 81, 94-104.

[18] Liang, T., Wang, N., Li, W., Li, A., et al., Identification of complement C3f-desArg and its derivative for acute leukemia diagnosis and minimal residual disease assessment. Proteomics, 10, 9098.

[19] Marshall, J., Kupchak, P., Zhu, W., Yantha, J., et al., Processing of serum proteins underlies the mass spectral fingerprinting of myocardial infarction. J Proteome Res 2003, 2, 361-372.

[20] Zhang, Z., Bast, R. C., Jr., Yu, Y., Li, J., et al., Three biomarkers identified from serum proteomic analysis for the detection of early stage ovarian cancer. Cancer Res 2004, 64, 5882-5890.

[21] Orvisky, E., Drake, S. K., Martin, B. M., Abdel-Hamid, M., et al., Enrichment of low molecular weight fraction of serum for MS analysis of peptides associated with hepatocellular carcinoma. Proteomics 2006, 6, 2895-2902.

[22] Pang, R. T., Poon, T. C., Chan, K. C., Lee, N. L., et al., Serum proteomic fingerprints of adult patients with severe acute respiratory syndrome. Clin Chem 2006, 52, 421-429.

[23] Koomen, J. M., Shih, L. N., Coombes, K. R., Li, D., et al., Plasma protein profiling for diagnosis of pancreatic cancer reveals the presence of host response proteins. Clin Cancer Res 2005, 11, 11101118. 


\section{Figure 1:}

Averaged MALDI-TOF mass spectra of human serum samples collected for UKCTOCS (upper panel) and UKOPS (lower panel) and obtained from purifications of $5 \mu \mathrm{L}$-aliquots using pre-packed $\mathrm{C} 18$ ZipTips $^{\circledR}$. Averaged mass spectra were generated by ClinProTools software v2.1 after baseline subtraction, smoothing, normalisation and peak realignment.

\section{Figure 2:}

Venn diagram showing the number of overlapping and total number of peptides identified in this study and those of the studies of Villanueva et al. [11] and Peng et al. [14]. 
Table 1. List of MALDI MS profile peaks

\begin{tabular}{|c|c|c|c|c|c|c|c|}
\hline \multirow{2}{*}{$\begin{array}{l}\text { Calculated } \\
\text { Monoisot. } \\
{[\mathbf{M}+\mathbf{H}]^{+}}\end{array}$} & \multirow{2}{*}{$\begin{array}{l}\text { Calculated } \\
\text { Average } \\
{[\mathrm{M}+\mathrm{H}]^{+}} \\
\end{array}$} & \multicolumn{2}{|c|}{ Protein/Peptide or Lipid } & \multirow[t]{2}{*}{ Peptide Sequences Identified } & \multicolumn{3}{|c|}{ Study } \\
\hline & & $\begin{array}{l}\text { UniProt } \\
\text { Entry }\end{array}$ & Name (Fragment) & & Tiss et al. & $\begin{array}{c}\text { Villanueva et } \\
\text { al. }\end{array}$ & Peng et al. \\
\hline 445.2518 & 445.4944 & P02671 & FPA (12-16) & E.GGGVR & $\sqrt{ }$ & & \\
\hline 496.3426 & & NA & $\operatorname{PC}(16: 0 / 0: 0)$ & NA & $\sqrt{ }$ & & \\
\hline 518.3236 & & NA & $\operatorname{PC}(18: 3 / 0: 0)$ & NA & $\sqrt{ }$ & & \\
\hline 520.3393 & & NA & $\operatorname{PC}(18: 2 / 0: 0)$ & NA & $\sqrt{ }$ & & \\
\hline 522.3590 & & NA & $\operatorname{PC}(18: 1 / 0: 0)$ & NA & $\sqrt{ }$ & & \\
\hline 524.3742 & & NA & $\operatorname{PC}(18: 0 / 0: 0)$ & NA & $\sqrt{ }$ & & \\
\hline 574.2944 & 574.6087 & P02671 & FPA (11-16) & A. EGGGVR & $\sqrt{ }$ & & \\
\hline 645.3315 & 645.6867 & P02671 & FPA (10-16) & L.AEGGGVR & $\sqrt{ }$ & & \\
\hline 740.2846 & 740.7172 & P02675 & FPB (1-7) $-\mathrm{NH}_{3}-\mathrm{H}_{2} \mathrm{O}$ & $\mathrm{Q}_{(-\mathrm{NH} 3)} \mathrm{GVND}_{(-\mathrm{H} 2 \mathrm{O})} \mathrm{NE} . \mathrm{E}$ & $\sqrt{ }$ & & \\
\hline 758.4155 & 758.8522 & P02671 & FPA $(9-16)$ & F. LAEGGGVR & $\sqrt{ }$ & $\sqrt{ }$ & \\
\hline 758.5701 & & NA & $\mathrm{PC}(16: 0 / 18: 2$ or $18: 0 / 16: 2)$ & NA & $\sqrt{ }$ & & \\
\hline 760.5915 & & NA & $\mathrm{PC}(16: 0 / 18: 1$ or $18: 0 / 16: 1)$ & NA & $\sqrt{ }$ & & \\
\hline 822.4297 & 822.9731 & P10909 & Clusterin precursor (217-222) & P.HFFFPK.S & & $\sqrt{ }$ & \\
\hline 842.3944 & 842.9214 & Q14624 & ITIH4 (681-687) & D. HAAYHPF.R & & $\sqrt{ }$ & \\
\hline 864.4097 & 864.9299 & P02671 & FPA $(7-15)$ & D.DFLAEGGGV.R & $\sqrt{ }$ & & \\
\hline 869.3272 & 869.8334 & P02675 & FPB $(1-8)-\mathrm{NH}_{3}-\mathrm{H}_{2} \mathrm{O}$ & $\mathrm{Q}_{(-\mathrm{NH} 3)} \mathrm{GVND}_{(-\mathrm{H} 20)} \mathrm{NEE} . \mathrm{G}$ & $\sqrt{ }$ & & \\
\hline 904.4676 & 905.0324 & P01042 & Bradykinin (1-8) & RPPGFSPF.R & & $\sqrt{ }$ & \\
\hline 905.4839 & 906.0288 & P02671 & FPA (8-16) & D. FLAEGGGVR & $\sqrt{ }$ & $\sqrt{ }$ & \\
\hline 920.4624 & 921.0385 & P01042 & Bradykinin (1-8) [Pro_Hydroxyl] & $\operatorname{RPPGFSP}_{(\text {Hydroxy1) }} \mathrm{F} \cdot \mathrm{R}$ & $\sqrt{ }$ & $\sqrt{ }$ & \\
\hline 926.3486 & 926.8856 & P02675 & FPB (1-9) $-\mathrm{NH}_{3}-\mathrm{H}_{2} \mathrm{O}$ & $\mathrm{Q}_{(-\mathrm{NH} 3)} \mathrm{GVND}_{(-\mathrm{H} 2 \mathrm{O})} \mathrm{NEEG} . \mathrm{F}$ & $\sqrt{ }$ & & \\
\hline 942.4680 & 943.0358 & P01024 & Complement C3f fragment (9-16) & I. HWESASLL.R & & $\sqrt{ }$ & \\
\hline 944.3592 & 944.8817 & P02675 & $\mathrm{FPB}(1-9)-\mathrm{NH}_{3}$ & $Q_{(-N H 3)}$ GVNDNEEG . F & $\sqrt{ }$ & & \\
\hline 991.6807 & & NA & $\operatorname{PC}(16: 0 / 0: 0)$ dimer & NA & $\sqrt{ }$ & & \\
\hline 998.4955 & 999.1075 & Q14624 & ITIH4 (681-688) & D. HAAYHPFR. & & $\sqrt{ }$ & \\
\hline 1015.6831 & & NA & $\operatorname{PC}(16: 0 / 0: 0)+\operatorname{PC}(18: 2 / 0: 0)$ dimer & NA & $\sqrt{ }$ & & \\
\hline 1020.5108 & 1021.1174 & P02671 & FPA (7-16) & G. DFLAEGGGVR & $\sqrt{ }$ & $\sqrt{ }$ & \\
\hline 1055.5520 & 1056.1937 & P01024 & Complement C3f fragment (8-16) & R. IHWESASLL. R & & $\sqrt{ }$ & \\
\hline 1060.5787 & 1061.2185 & P01042 & Bradykinin & RPPGFSPFR & & $\sqrt{ }$ & \\
\hline 1073.4171 & 1074.0634 & P02675 & FPB $(1-10)-\mathrm{NH}_{3}-\mathrm{H}_{2} \mathrm{O}$ & $\mathrm{Q}_{(-\mathrm{NH} 3)} \mathrm{GVND}_{(-\mathrm{H} 2 \mathrm{O})} \mathrm{NEEGF} . \mathrm{F}$ & $\sqrt{ }$ & & \\
\hline 1076.5736 & 1077.2179 & P01042 & Bradykinin [Pro_Hydroxyl] & $\operatorname{RPPGFSP}_{(\text {Hydroxy1) }} \mathrm{FR}$ & & $\sqrt{ }$ & \\
\hline 1077.5323 & 1078.1693 & P02671 & FPA (6-16) & E. GDFLAEGGGVR & $\sqrt{ }$ & $\sqrt{ }$ & \\
\hline 1091.4277 & 1092.0559 & P02675 & $\mathrm{FPB}(1-10)-\mathrm{NH}_{3}$ & $\mathrm{Q}_{(-\mathrm{NH} 3)}$ GVNDNEEGF . F & $\sqrt{ }$ & & \\
\hline 1108.4542 & 1109.1005 & P02675 & FPB $(1-10)$ & QGVNDNEEGF.F & $\sqrt{ }$ & & \\
\hline 1194.5273 & 1195.2274 & P02671 & FPA (3-15) & D.SGEGDFLAEGGGV.R & $\sqrt{ }$ & & \\
\hline 1206.5749 & 1207.2848 & P02671 & FPA $(5-16)$ & G. EGDFLAEGGGVR & $\sqrt{ }$ & $\sqrt{ }$ & \\
\hline 1211.6531 & 1212.3798 & P01024 & Complement $\mathrm{C} 3 \mathrm{f}$ fragment (7-16) & H. RIHWESASLL.R & & $\sqrt{ }$ & \\
\hline 1220.4855 & 1221.2413 & P02675 & FPB $(1-11)-\mathrm{NH}_{3}-\mathrm{H}_{2} \mathrm{O}$ & $\mathrm{Q}_{(-\mathrm{NH} 3)} \mathrm{GVND}_{(-\mathrm{H} 2 \mathrm{O})}$ NEEGFF.S & $\sqrt{ }$ & & \\
\hline 1238.4961 & 1239.2519 & P02675 & $\mathrm{FPB}(1-11)-\mathrm{NH}_{3}$ & $\mathrm{Q}_{(-\mathrm{NH} 3)}$ GVNDNEEGFF.S & $\sqrt{ }$ & & \\
\hline 1263.5963 & 1264.3367 & P02671 & FPA (4-16) & S. GEGDFLAEGGGVR & $\sqrt{ }$ & $\sqrt{ }$ & \\
\hline
\end{tabular}




\begin{tabular}{|c|c|c|c|c|}
\hline 1277.7153 & 1278.5258 & P10909 & Clusterin precursor (217-226) & P. HFFFPKSRIV.R \\
\hline 1309.5542 & 1310.3160 & P02671 & FPA (2-15) & A. DSGEGDFLAEGGGV. $R$ \\
\hline 1325.5281 & 1326.3076 & P02675 & FPB $(1-12)-\mathrm{NH}_{3}$ & $\mathrm{Q}_{(-\mathrm{NH})}$ GVNDNEEGFFS . A \\
\hline 1348.7120 & 1349.5194 & P01024 & Complement C3f fragment (6-16) & T. HRIHWESASLL. R \\
\hline 1350.6284 & 1351.4149 & P02671 & FPA (3-16) & D.SGEGDFLAEGGGVR \\
\hline 1396.5652 & 1397.4098 & P02675 & $\mathrm{FPB}(1-13)-\mathrm{NH}_{3}$ & $\mathrm{Q}_{(-\mathrm{NH} 3)}$ GVNDNEEGFFSA.R \\
\hline 1447.6447 & 1448.4929 & P02671 & FPA $(2-16)-\mathrm{H}_{2} \mathrm{O}$ & A. DS $(-\mathrm{H} 20)$ GEGDFLAEGGGVR \\
\hline 1449.7597 & 1450.6235 & P01024 & Complement $\mathrm{C} 3$ f fragment $(5-16)$ & I. THRIHWESASLL.R \\
\hline 1465.6554 & 1466.5035 & P02671 & FPA (2-16) & A. DSGEGDFLAEGGGVR \\
\hline 1498.7873 & 1499.6562 & POCOL4 & Complement C4-A (1337-1349) & R.NGFKSHALQLNNR.Q \\
\hline 1518.6818 & 1519.5717 & P02671 & $\mathrm{FPA}-\mathrm{H}_{2} \mathrm{O}$ & $\operatorname{ADS}_{(-\mathrm{H} 20)} \mathrm{GEGDFLAEGGGVR}$ \\
\hline 1530.8692 & 1531.8273 & Q59FS1 & IGIH4 & R.RPHFFFPKSRIV.R \\
\hline 1536.6924 & 1537.5823 & P02671 & FPA & ADSGEGDFLAEGGGVR \\
\hline 1542.5939 & 1543.4566 & P02671 & FGA chain (605-619) & A. DEAGSEADHEGTHST . K \\
\hline 1545.6000 & 1546.4482 & P02671 & $\mathrm{FPA}(2-16)+\mathrm{P}$ & A. DS $\mathrm{p}_{\mathrm{p}} \mathrm{GEDFLAEGGGVR}$ \\
\hline 1562.8438 & 1563.7813 & P01024 & Complement C3f fragment (4-16) & K. ITHRIHWESASLL. R \\
\hline 1616.6594 & 1617.5493 & P02671 & $\mathrm{FPA}+\mathrm{P}$ & ADS $_{p}$ GEGDFLAEGGGVR \\
\hline 1626.8459 & 1627.7857 & POCOL4 & Complement C4-A (1337-1350) & R.NGFKSHALQLNNRQ. I \\
\hline 1690.9387 & 1691.9540 & P01024 & Complement C3f fragment (3-16) & S. KITHRIHWESASLL. R \\
\hline 1739.9299 & 1740.9619 & POCOL4 & Complement C4-A (1337-1351) & R.NGFKSHALQLNNRQI.R \\
\hline 1751.9187 & 1752.9510 & P01024 & Complement C3f fragment (1-15) & .SSKITHRIHWESASL.L \\
\hline 1762.9222 & 1763.9653 & POCOL4 & Complement C4-A (1353-1368) & R.GLEEELQFSLGSKINV. K \\
\hline 1768.8236 & 1769.8406 & P01024 & Complement C3 (1322-1337) & S. EETKENEGFTVTAEGK. G \\
\hline 1771.8497 & 1772.8893 & P06727 & Apolipoprotein A-IV (288-303) & K.SLAELGGHLDQQVEEF. R \\
\hline 1777.9708 & 1779.0314 & P01024 & Complement $\mathrm{C} 3$ f fragment $(2-16)$ & S.SKITHRIHWESASLL.R \\
\hline 1786.8547 & 1787.9504 & Q14624 & ITIH4 (671-687) & L.GLPGPPDVPDHAAYHPF.R \\
\hline 1807.9297 & 1808.9884 & P02647 & Apolipoprotein A-I (149-163) & A. ELQEGARQKLHELQE.K \\
\hline 1847.8379 & 1848.8859 & P02671 & FGA chain $(607-624)$ & E. AGSEADHEGTHSTKRGHA.K \\
\hline 1855.8555 & 1856.9375 & P01024 & Complement C3 (1321-1337) & R.SEETKENEGFTVTAEGK. G \\
\hline 1865.0028 & 1866.1295 & P01024 & Complement C3f fragment (1-16) & SSKITHRIHWESASLL. R \\
\hline 1883.8114 & 1884.8701 & P02671 & FGA chain $(605-622)$ & A. DEAGSEADHEGTHSTKRG. H \\
\hline 1884.9899 & 1886.0639 & P02671 & FGA chain $(606-622)$ & D. HEGTHSTKRGHAKSRPV.R \\
\hline 1896.0311 & 1897.1494 & P0C0L4 & Complement C4-A (1336-1351) & G. RNGFKSHALQLNNRQI.R \\
\hline 1927.9508 & 1929.0755 & P06727 & Apolipoprotein A-IV (288-304) & K.SLAELGGHLDQQVEEFR.R \\
\hline 1943.9080 & 1945.0261 & P01042 & HMW Kininogen (440-456) & H. NLGHGHKHERDQGHGHQ. R \\
\hline 1971.0433 & 1972.2228 & P02647 & Apolipoprotein A-I (251-267) & K.VSFLSALEEYTKKLNTQ \\
\hline 2008.0788 & 2009.3518 & Q0P5N8 & TMSB4X (31-47) & K. PDMAEIEKFDKSKLKKT.E \\
\hline 2010.9708 & 2012.2352 & Q14624 & ITIH4 (669-687) $-\mathrm{NH}_{3}$ & $\mathrm{R} \cdot \mathrm{Q}_{(-\mathrm{NH})} \mathrm{LGLPGPPDVPDHAAYHP}$ \\
\hline 2021.1039 & 2022.2950 & P01024 & Complement $\mathrm{C} 3 \mathrm{f}$ fragment & SSKITHRIHWESASLLR \\
\hline 2027.9974 & 2029.2378 & Q14624 & ITIH4 (669-687) & R.QLGLPGPPDVPDHAAYHPF.R \\
\hline 2045.9172 & 2047.1100 & P01042 & HMW Kininogen (480-497) & L. DDDLEHQGGHVLDHGHKH.K \\
\hline 2053.0812 & 2054.2822 & P02647 & Apolipoprotein A-I (220-238) & K. ATEHLSTLSEKAKPALEDL . R \\
\hline 2067.1921 & 2068.4016 & P02775 & Platelet Basic Protein precursor (110-127) & D. APRIKKIVQKKLAGDESAD \\
\hline
\end{tabular}




\begin{tabular}{|c|c|c|c|}
\hline 2091.9074 & 2093.0900 & P02671 & FGA chain (605-624) \\
\hline 2113.0771 & 2114.3166 & Q0P5N8 & TMSB4X (52-70) \\
\hline 2115.0512 & 2116.3462 & Q14624 & (ITIH4) (347-367) \\
\hline 2122.8618 & 2124.1563 & P02671 & FGA chain $(600-619)$ \\
\hline 2127.0128 & 2128.2565 & P01042 & HMW Kininogen (458-477) \\
\hline 2162.9445 & 2164.1688 & P02671 & FGA chain (604-624) \\
\hline 2184.0985 & 2185.4238 & Q14624 & ITIH4 (669-688) \\
\hline 2209.0619 & 2210.3192 & P01042 & HMW Kininogen (438-456) \\
\hline 2267.1891 & 2268.5127 & P02649 & Apolipoprotein E (212-232) \\
\hline 2271.1305 & 2272.5274 & Q14624 & ITIH4 (667-687) \\
\hline 2279.2718 & 2280.6046 & P02775 & Platelet Basic Protein precursor (108-127) \\
\hline 2305.2034 & 2306.5524 & P0C0L4 & Complement C4-A (1353-1374) \\
\hline 2353.1518 & 2354.5363 & Q0P5N8 & TMSB4X $(50-70)-\mathrm{NH}_{3}$ \\
\hline 2358.1626 & 2359.5787 & Q14624 & ITIH4 (666-687) \\
\hline 2371.1624 & 2372.5469 & Q0P5N8 & TMSB4X (50-70) \\
\hline 2378.2098 & 2379.6342 & P0C0L4 & Complement C4-A (1429-1449) \\
\hline 2379.0371 & 2380.4173 & P02671 & FGA (577-597) \\
\hline 2409.2633 & 2410.6688 & P02649 & Apolipoprotein E (210-232) \\
\hline 2451.2051 & 2452.6608 & P02766 & Transthyretin precursor $(101-123)$ \\
\hline 2453.9610 & 2455.4140 & Q0P5N8 & TMSB4X (49-70) $-\mathrm{NH}_{3}$ \\
\hline 2464.0793 & 2465.5698 & P02671 & FGA chain $(600-622)$ \\
\hline 2471.2260 & 2472.6679 & Q0P5N8 & TMSB4X (49-70) \\
\hline 2508.3529 & 2509.7985 & P06727 & Apolipoprotein A-IV (256-278) \\
\hline 2544.2297 & 2545.6650 & P02671 & FGA chain (606-629) \\
\hline 2551.1769 & 2552.7529 & P0C0L4 & Complement C4-A (957-979) \\
\hline 2553.1012 & 2554.5991 & P02671 & FGA chain (576-598) \\
\hline 2565.3644 & 2566.8549 & P02649 & Apolipoprotein E (210-233) \\
\hline 2567.3729 & 2568.9088 & P02768 & Albumin precursor (27-48) \\
\hline 2582.3402 & 2583.9185 & Q14624 & ITIH4 (617-639) \\
\hline 2599.2635 & 2600.7734 & $\mathrm{P} 02647$ & Apolipoprotein A-IV (280-303) \\
\hline 2602.3107 & 2603.8204 & P00488 & Factor XIIIIa (14-38) \\
\hline 2627.3400 & 2628.9194 & Q14624 & ITIH4 (663-687) \\
\hline 2659.2567 & 2660.7791 & P02671 & FGA chain (605-629) \\
\hline 2704.4516 & 2706.0385 & P0C0L4 & Complement C4-A (1353-1378) \\
\hline 2724.3893 & 2726.0348 & Q14624 & ITIH4 (662-687) \\
\hline 2753.4369 & 2755.1053 & P02768 & Albumin precursor (25-48) \\
\hline 2755.3646 & 2756.9595 & P06727 & Apolipoprotein A-IV (280-304) \\
\hline 2768.2282 & 2769.8514 & P02671 & FGA chain $(576-600)$ \\
\hline 2778.4520 & 2780.0741 & $\mathrm{P} 02654$ & Apolipoprotein C-I (29-53) \\
\hline 2816.3234 & 2817.9581 & P02671 & FGA (548-574) \\
\hline 2829.4112 & 2831.0626 & Q0P5N8 & TMSB4X (46-70) \\
\hline 2861.3343 & 2863.6505 & P02671 & FGA chain (603-629) \\
\hline 2931.2915 & 2933.0274 & P02671 & FGA chain precursor (576-601) \\
\hline
\end{tabular}

A. DEAGSEADHEGTHSTKRGHA.K

E. KNPLPSKETIEQEKQAGES

R. NVHSAGAAGSRMNFRPGVLSS.R

K. SYKMADEAGSEADHEGTHST . K

R. GHGLGHGHEQQHGLGHGHKF . K

M. ADEAGSEADHEGTHSTKRGHA.K

$R$. QLGLPGPPDVPDHAAYHPFR . R

R. KHNLGHGHKHERDQGHGHQ. R

A. TVGSLAGQPLQERAQAWGERL.R

S. SRQLGLPGPPDVPDHAAYHPF.R

D. PDAPRIKKIVQKKLAGDESAD

R. GLEEELQFSLGSKINVKVGGNS. K

T. QEKN ${ }_{(-\mathrm{NH})}$ PLPSKETIEQEKQAGES

S. SSRQLGLPGPPDVPDHAAYHPF.R

T. QEKN (deam) $_{\text {PLPSKETIEQEKQAGES }}$

K. DDPDAPLQPVTPLQLFEGRR . R

S. SSYSKQFTSSTSYNRGDSTFE.S

R. AATVGSLAGQPLQERAQAWGERL . $R$

K. ALGISPFHEHAEVVFTANDSGPR. $R$

E. TQ ${ }_{(-N H 3)}$ EKNPLPSKETIEQEKQAGES

K. SYKMADEAGSEADHEGTHSTKRG. H

E. TQEKNPLPSKETIEQEKQAGES

R. ISASAEELRQRLAPLAEDVRGNL . K

D. EAGSEADHEGTHSTKRGHAKSRPV.R

R. TLEIPGNSDPNMIPDGDFNSYVR.V

K. SSSYSKQFTSSTSYNRGDSTFES.K

R. AATVGSLAGQPLQERAQAWGERLR. A

A. HKSEVAHRFKDLGEENFKALVL. I

R.NVHSGSTFFKYYLQGAKIPKPEA.S

K . GNTEGLQKSLAELGGHLDQQVEEF . R

R. AVPPNNSNAAEDDLPTVELQGVVPR. G

P. GVLSSRQLGLPGPPDVPDHAAYHPF . R

A. DEAGSEADHEGTHSTKRGHAKSRPV.R

R. GLEEELQFSLGSKINVKVGGNSKGTL. $K$

R. PGVLSSRQLGLPGPPDVPDHAAYHPF . R

R. DAHKSEVAHRFKDLGEENFKALVL. I

K. GNTEGLOKSLAELGGHLDQQVEEFR .

K. SSSYSKQFTSSTSYNRGDSTFESKS. Y

P.DVSSALDKLKEFGNTLEDKARELIS.R

R.GSESGIFTNTKESSSHHPGIAEFPSRG . K

K. KTETQEKNPLPSKETIEQEKQAGES

K. MADEAGSEADHEGTHSTKRGHAKSRPV.R

K. SSSYSKQFTSSTSYNRGDSTFESKSY.K

\begin{tabular}{|c|c|c|}
\hline & $\sqrt{ }$ & \\
\hline 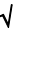 & $\sqrt{ }$ & \\
\hline 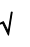 & & \\
\hline & $\sqrt{ }$ & \\
\hline & $\sqrt{ }$ & $\sqrt{ }$ \\
\hline & $\sqrt{ }$ & \\
\hline$\sqrt{ }$ & $\sqrt{ }$ & $\sqrt{ }$ \\
\hline & $\sqrt{ }$ & $\sqrt{ }$ \\
\hline & $\sqrt{ }$ & \\
\hline & & \\
\hline & $\sqrt{ }$ & \\
\hline 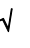 & & \\
\hline & & \\
\hline & $\sqrt{ }$ & \\
\hline & $\sqrt{ }$ & \\
\hline & $\sqrt{ }$ & \\
\hline$y$ & & \\
\hline$\sqrt{ }$ & & \\
\hline & & \\
\hline & $\sqrt{ }$ & \\
\hline & $\sqrt{ }$ & \\
\hline$\sqrt{ }$ & $\sqrt{ }$ & \\
\hline & $\sqrt{ }$ & \\
\hline v & & \\
\hline & & \\
\hline & $\sqrt{ }$ & \\
\hline & $\sqrt{ }$ & \\
\hline & $\sqrt{ }$ & \\
\hline$\sqrt{ }$ & $\sqrt{ }$ & $\sqrt{ }$ \\
\hline & $\sqrt{ }$ & \\
\hline & $\sqrt{ }$ & \\
\hline$\sqrt{ }$ & & \\
\hline & $\sqrt{ }$ & \\
\hline$\sqrt{ }$ & $\sqrt{ }$ & $\sqrt{ }$ \\
\hline & $\sqrt{ }$ & \\
\hline & $\sqrt{ }$ & \\
\hline & & \\
\hline & & $y$ \\
\hline & $\sqrt{ }$ & $\sqrt{ }$ \\
\hline
\end{tabular}




\begin{tabular}{|c|c|c|c|c|c|c|c|}
\hline 2989.4292 & 2991.2246 & $\mathrm{P} 02671$ & FGA chain $(602-629)$ & Y. KMADEAGSEADHEGTHSTKRGHAKSRPV.R & $\sqrt{ }$ & & \\
\hline 3156.6265 & 3158.5491 & Q14624 & ITIH4 (617-644) & R. NVHSGSTFFKYYLQGAKIPKPEASFSPR.R & $\sqrt{ }$ & $\sqrt{ }$ & $\sqrt{ }$ \\
\hline 3182.7347 & 3184.6627 & P02647 & Apolipoprotein A-I (240-267) & R. QGLLPVLESFKVSFLSALEEYTKKLNTQ & & $\sqrt{ }$ & \\
\hline 3190.4270 & 3192.3659 & P02671 & FGA (576-603) & K.SSSYSKQFTSSTSYNRGDSTFESKSYKM. A & & $\sqrt{ }$ & $\sqrt{ }$ \\
\hline 3200.8001 & 3202.6864 & POCOL4 & Complement C4-A (1353-1382) & R. GLEEELQFSLGSKINVKVGGNSKGTLKVLR.T & & $\sqrt{ }$ & \\
\hline 3206.4219 & 3208.3653 & $\mathrm{P} 02671$ & FGA (576-603) [Met-ox] & K. SSSYSKQFTSSTSYNRGDSTFESKSYKM & & $\sqrt{ }$ & \\
\hline 3239.5246 & 3241.4788 & P02671 & FGA chain $(600-629)$ & K. SYKMADEAGSEADHEGTHSTKRGHAKSRPV.R & $\sqrt{ }$ & $\sqrt{ }$ & $\sqrt{ }$ \\
\hline 3261.4641 & 3263.4440 & P02671 & FGA chain (576-604) & K. SSSYSKQFTSSTSYNRGDSTFESKSYKMA.D & $\sqrt{ }$ & $\sqrt{ }$ & $\sqrt{ }$ \\
\hline 3272.6422 & 3274.6954 & Q14624 & ITIH4 (658-687) & R. MNFRPGVLSSRQLGLPGPPDVPDHAAYHPF.R & $\sqrt{ }$ & $\sqrt{ }$ & \\
\hline 3277.4590 & 3279.4434 & $\mathrm{P} 02671$ & FGA (576-604) [Met-ox] & K. SSSYSKQFTSSTSYNRGDSTFESKSYKM ${ }_{\text {ox }}$ A. D & & $\sqrt{ }$ & \\
\hline 3377.7230 & 3379.7435 & P02647 & Apolipoprotein A-I (148-176) & R. AELQEGARQKLHELQEKLSPLGEEM ${ }_{0 x} R D R A . R$ & & $\sqrt{ }$ & \\
\hline 3675.9075 & 3678.0877 & Q0P5N8 & TMSB4X (39-70) & K. FDKSKLKKTETQEKNPLPSKETIEQEKQAGES & $\sqrt{ }$ & & \\
\hline 3953.9098 & 3956.4034 & Q14624 & ITIH4 (645-681) & R. RGWNRQAGAAGSRMNFRPGVLSSRQLGLPGPPDVPDH . A & $\sqrt{ }$ & & \\
\hline 3970.9882 & 3973.4255 & Q14624 & ITIH4 (650-687) & R. QAGAAGSRMNFRPGVLSSRQLGLPGPPDVPDHAAYHPF.R & & $\sqrt{ }$ & \\
\hline 4280.1319 & 4282.7883 & Q59FS1 & IGIH4 (602-642) & R. NVHSAGAAGSRMNFRPGVLSSRQLGLPGPPDVPDHAAYHPF.R & $\sqrt{ }$ & & $\sqrt{ }$ \\
\hline 4961.3111 & 4964.3899 & P02671 & FGA chain (529-574) or (513-558) & $\begin{array}{l}\text { T.FPGFFSPMLGEFVSETESRGSESGIFTNTKESSSHHPGIAEFPSRG.K } \text { or } \\
\text { R.HPDEAAFFDTASTGKTFPGFFSPMLGEFVSETESRGSESGIFTNTK.E }\end{array}$ & $\sqrt{ }$ & & \\
\hline 5334.3536 & 5337.5402 & P02671 & FGA chain $(577-624)$ & K. SSSYSKQFTSSTSYNRGDSTFESKSYKMADEAGSEADHEGTHSTKRGHA.K & $\sqrt{ }$ & & $\sqrt{ }$ \\
\hline 5901.7029 & 5905.2293 & P02671 & FGA chain $(577-629)$ & K. SSSYSKQFTSSTSYNRGDSTFESKSYKMADEAGSEADHEGTHSTKRGHAKSRPV.R & $\sqrt{ }$ & & $\sqrt{ }$ \\
\hline 6627.3167 & 6631.4463 & P02655 & Apolipoprotein C-II (32-90) & M. PSPTFLTQVKESLSSYWESAKTAAQNLYEKTYLPAVDEKLRDLYSKSTAAMSTYTGIFT . D & $\sqrt{ }$ & & \\
\hline 8200.0508 & 8205.1815 & P02655 & Apolipoprotein C-II (29-101) & $\begin{array}{l}\text { Q. DEMPSPTFLTQVKESLSSYWESAKTAAQNLYEKTYLPAVDEKLRDLYSKSTAAMSTYTGIF } \\
\text { TDQVLSVLKGEE }\end{array}$ & $\sqrt{ }$ & & \\
\hline 8760.2248 & 8765.6732 & P02656 & Apolipoprotein C-III & $\begin{array}{l}\text { SEAEDASLLSFMQGYMKHATKTAKDALSSVQESQVAQQARGWVTDGFSSLKDYWSTVKDKFSE } \\
\text { FWDLDPEVRPTSAVAA }\end{array}$ & $\sqrt{ }$ & & \\
\hline 8910.3855 & 8915.9261 & P02655 & Apolipoprotein C-II (Chain A) & $\begin{array}{l}\text { TQQPQQDEMPSPTFLTQVKESLSSYWESAKTAAQNLYEKTYLPAVDEKLRDLYSKSTAAMSTY } \\
\text { TGIFTDQVLSVLKGEE }\end{array}$ & $\sqrt{ }$ & & \\
\hline 9282.8208 & 9288.7182 & P02775 & CTAP-III & $\begin{array}{l}\text { NLAKGKEESLDSDLYAELRCMCIKTTSGIHPKNIQSLEVIGKGTHCNQVEVIATLKDGRKICL } \\
\text { DPDAPRIKKIVQKKLAGDESAD }\end{array}$ & $\sqrt{ }$ & & \\
\hline
\end{tabular}

* In the MS/MS spectra of these peaks, Choline, $\mathrm{H}_{2} \mathrm{O}$-Choline and PhosphoCholine peaks were dominant but no corresponding phospholipids were found in the LipidMaps database.

CTAP-III: Connective tissue-activating peptide III; FGA: Fibrinogen alpha; FPA: Fibrinopeptide A; FPB: Fibrinopeptide B; HMW Kininogen: High molecular weight kininogen; IGIH4: Inter-alpha (Globulin) inhibitor H4 (Plasma Kallikrein-sensitive glycoprotein) varaint; ITIH4: Inter-alpha-trypsin inhibitor heavy chain H4; NA: Not applicable; PC: Phophatidylcholine; TMSB4X: Thymosin, beta 4. [M+H] values were calculated using IsotopePattern Software (Bruker Daltonics). 


\section{Synopsis}

Despite the numerous reports on MALDI MS profiling of human serum there is only scarce information on the profile peaks' identities. Here, we provide a well-characterised list of peak identities obtained from human blood serum that can be used for provisional identification of these peaks and show that in-depth proteomic analysis of many thousands of peptides by (multidimensional) LC-ESI-MS/MS cannot provide the necessary information for identifying MALDI-generated profile peaks.

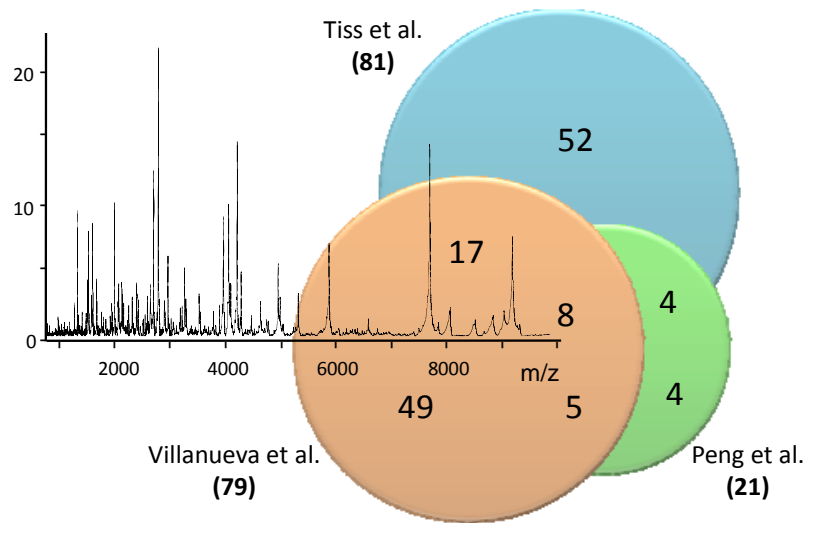

